\title{
André Gagné, Jean-François Racine (éd.), En marge du canon. Études sur les écrits apocryphes juifs et chrétiens
}

Paris, Éditions du Cerf, coll. «L'écriture de la Bible », 2012, 288 p.

\section{Mustapha Naïmi}

\section{CpenEdition}

Journals

Édition électronique

URL : http://journals.openedition.org/assr/24541

DOI : $10.4000 /$ assr.24541

ISSN : $1777-5825$

Éditeur

Éditions de l'EHESS

Édition imprimée

Date de publication : 30 décembre 2012

Pagination : 176

ISSN : 0335-5985

Référence électronique

Mustapha Naïmi, «André Gagné, Jean-François Racine (éd.), En marge du canon. Études sur les écrits apocryphes juifs et chrétiens », Archives de sciences sociales des religions [En ligne], 160 | octobredécembre 2012, mis en ligne le 12 mars 2013, consulté le 21 septembre 2020. URL : http:// journals.openedition.org/assr/24541; DOI : https://doi.org/10.4000/assr.24541

Ce document a été généré automatiquement le 21 septembre 2020.

(c) Archives de sciences sociales des religions 


\title{
André Gagné, Jean-François Racine (éd.), En marge du canon. Études sur les écrits apocryphes juifs et chrétiens
}

Paris, Éditions du Cerf, coll. «L'écriture de la Bible », 2012, 288 p.

\author{
Mustapha Naïmi
}

\section{RÉFÉRENCE}

André Gagné, Jean-François Racine (éd.) En marge du canon. Études sur les écrits apocryphes juifs et chrétiens, Paris, Éditions du Cerf, coll. «L'écriture de la Bible », 2012, $288 \mathrm{p}$.

1 Les actes du $65^{\mathrm{e}}$ congrès annuel de l'Association catholique des études bibliographiques au Canada (ACEBAC) portent sur les apocryphes juifs et chrétiens. Alors que les écrits canoniques appartiennent à la sphère ecclésiale, c'est-à-dire aux célébrations liturgiques des différentes confessions chrétiennes, aux facultés de théologie et séminaires chargés de former les différents ministres, aux librairies religieuses, les écrits apocryphes appartiennent à la sphère séculière, c'est-à-dire aux départements de sciences religieuses et aux librairies à grande surface. Même s'il n'est pas aisé de rapprocher ces deux sphères dans un même essai, les actes tentent de les situer l'un par rapport à l'autre en un rapport étroit, en fait si étroit qu'il suggère de considérer les écrits canoniques et les écrits apocryphes comme un couple bien assorti. C'est ce qu'analyse Jean-François Racine en insistant sur les problèmes de terminologie et de définitions. Il distingue certains modèles relationnels tels que le canon en tant qu'espace herméneutique ou comme source de frustration.

2 De son côté, Jean-Paul Michaud traite des textes canoniques relatifs aux faits qui retracent le récit de Jésus de Nazareth, le Jésus de l'histoire. Ces textes, réduits aux 
Évangiles canoniques, introduisent les sources primaires tels que l'Évangile selon saint Thomas, l'Évangile Egerton, l'Évangile de Pierre, sont considérés par l'auteur comme sources possibles. Il examine cinq des principaux documents constamment invoqués ou exploités dans la recherche actuelle ; celles invoquées ci-dessus et l'Évangile de Marc et l'Évangile de Saint Thomas.

3 Pour délimiter les frontières du champ apocryphe, Paul-Hubert Poirier procède en trois temps : la situation jusqu'à la fin de 1970, le changement de paradigme survenu au cours des années 1980 et les discussions qui s'en sont suivies. Il plaide pour le retour à l'hypertextualité et à la pseudépigraphie. Il plaide pour la libération des apocryphes de leur position de Nouveau Testament qui a longtemps été la leur. Il lui importe de considérer ces textes pour ce qu'ils sont, une partie intégrante de littérature chrétienne ancienne et médiévale. Une lecture historique ne saurait faire l'objet d'aucun monopole.

4 De son côté, Marie-Françoise Baslez traite de la mémoire et de l'histoire des persécutions dans la littérature apocryphe juive et chrétienne. Elle trouve que les textes apocryphes juifs et chrétiens renseignent sur la manière dont ces communautés ont structuré leur identité à travers des figures et des récits fondateurs. Elle traite du modèle historiographique : les livres de Maccabées. Ce sont deux apocryphes juifs, le premier et le deuxième livre des Maccabées, réintégrés dans les Bibles chrétiennes sous le titre de Livre des martyrs juifs, qui donnent les clés d'un nouveau mode d'écriture et d'histoire présenté dans deux textes à caractère programmatique. L'auteur trouve qu'on est en droit de lire cette tradition apocryphe comme une écriture qui s'apparente à celle des mythes fondateurs, participant d'une construction identitaire.

5 L'Apocalypse syriaque de Daniel fait l'objet d'un essai de compréhension fondée sur la structure du texte par Pierre Cardinal. L'auteur considère le texte lui-même et pour luimême, ce qui permet d'établir la structure globale du récit de révélation. Le récit d'introduction s'amorce par un rappel des six premiers chapitres du « Livre de Daniel », ceux dont l'action se situe à la cour du roi Nabuchodonosor. La comparaison avec la tradition dont le récit s'inspire permet de faire ressortir le caractère propre du nouveau récit, et par-delà de mieux saisir les objectifs poursuivis par l'auteur. La lecture typologique proposée à travers ces images n'est pas destinée à soutenir les discours prophétiques de l'exil, mais sert plutôt à illustrer certaines réalités du parcours des justes dans leur route vers le ciel. L'examen de la révélation de Daniel requiert une posture exégétique conséquente. L'organisation interne du texte se veut porteuse de signification. L'Apocalypse syriaque de Daniel repose donc sur une certaine compréhension de l'avenir qui implique une vision différente de la religion d'Israël. Ce cadre d'interprétation est certes chrétien, mais il s'inscrit encore pleinement dans les catégories du judaïsme.

Jean-Michel Roessli traite du récit de la passion dans les oracles sibyllins. Il isole quelques fragments des textes relatifs à la Passion tirés des premier, sixième et huitième livres des "Oracles sibyllins", de les comparer entre eux et avec les épisodes correspondants dans le Nouveau Testament, de manière à évaluer le mode de réécriture, les points de contact, les liens de dépendance éventuels et les points de divergences. L'auteur se sent parfaitement libre d'utiliser ses sources (la Bible et les Oracles sibyllins) selon sa propre vision et en leur donnant l'orientation qu'il souhaitait. 
7 L'Évangile de Judas, cinq ans après sa (re)découverte, est mis à jour par Serge Cazelais. Cet article situe d'abord l'EvJudas et donne un bref aperçu de son contenu. S'ensuit l'examen philologique de trois extraits significatifs du texte là où les progrès de l'édition critique, l'apport des nouveaux fragments et une meilleure compréhension de la syntaxe parfois difficile de la langue copte du texte, ont permis d'améliorer la lecture de l'EvJudas depuis la première vague de publications. L'auteur explore enfin quelques rapports qu'entretient l'EvJudas avec les évangiles canoniques et le livre des Actes des apôtres.

8 L'auteur trouve qu'au moyen des premiers mots qu'il utilise, l'auteur de l'EvJudas inviterait son lecteur à la prudence et à faire montre d'une certaine subtilité et de persévérance afin d'accéder à la clé herméneutique qui lui ouvrira les portes de l'interprétation de son œuvre, une œuvre difficile qui pourrait contenir plus d'un niveau de lecture.

De son côté, André Gagné se charge de lire un apocryphe en synchronie. Il procède à une analyse structurelle et intertextuelle du logion 22 de l'Évangile selon Thomas. Constatant qu'il n'existe aucun parallèle de texte parmi les papyri d'Oxyrhynque, il commence par offrir au lecteur une traduction française du texte copte. Il s'attarde sur l'interprétation du logion 22 de l'EvTh. L'analyse structurale montre bien le lien qui existe entre la parole initiale de Jésus sur les petits et l'entrée dans le Royaume (l'EvTh 22, 1-2), et la réponse qu'il donne face à la méprise des disciples (l'EvTh 22, 3-7). Il insiste sur la nécessité de se tourner du côté de l'interprétation de la collection de paroles comme un tout. Cela conduit à une quête de sens qui affecte la dimension existentielle de ceux qui s'engagent dans l'interprétation des paroles cachées de Jésus.

10 Pierluigi Piovanelli traite de quelques considérations rétrospectives et prospectives de la part d'un "vétéran » de l'Enoch Seminar. Il s'agit du séminaire regroupant des spécialistes nord-américains, européens et israéliens du judaïsme du second Temple et des origines chrétiennes, qui a été fondé par Gabrielle Boccaccini, de l'Université de Michigan, au tournant du millénaire. La dimension philologique a pour finalité de faire de l'Enoch Seminar une caisse de résonnance et une plateforme de discussion pour ce qui se fait, souvent ailleurs, dans la recherche contemporaine. La translittération du guèze a dominé la version éthiopienne du $1^{\text {er }}$ Hénochoù, le Dictionnaire comparatif de Wolf Leslau, paru en 1987, qui se base sur la prononciation traditionnelle éthiopienne du guèze, et non de la vieille introduction grammaticale, certes utile, mais à maints égards inadéquate, voire carrément fautive, de Thomas O. Lambdin.

11 Une dernière illusion d'optique que les travaux les plus récents de l'Enoch Seminar devraient contribuer à corriger concerne la vieille querelle d'une opposition présumée entre la prophétie israélienne ancienne, préservée dans la Bible hébraïque, et l'apocalyptique juive tardive, rejetée dans les marges douteuses de la pseudépigraphie et l'apocryphité. En réalité, dès que nous commençons à porter un regard moins théologique et davantage interculturel anthropologique et littéraire sur la surproduction scripturaire dont témoignent les innombrables textes parabibliques des bibliothèques de Qumrân, les ouvrages pseudépigraphiques en circulation dans la diaspora juive hellénistique et tous les récits "apocryphes » des premiers siècles du christianisme, nous nous rendons facilement compte qu'il s'agit d'un seul et unique phénomène global de réécriture interprétative et actualisante des traditions mémoriales sur les origines. 